\title{
Safety Indications of Navigation Audit for Tankers to Develop a Bridge Inspection Method
}

\author{
Murat Hasan Ali Altun, Serdar Kum \\ Maritime Faculty, Istanbul Technical University, Istanbul, Turkey \\ Email: maltun@itu.edu.tr, kumse@itu.edu.tr
}

How to cite this paper: Altun, M.H.A. and Kum, S. (2019) Safety Indications of Navigation Audit for Tankers to Develop a Bridge Inspection Method. Journal of Computer and Communications, 7, 18-33. https://doi.org/10.4236/jcc.2019.71003

Received: December 20, 2018

Accepted: January 19, 2019

Published: January 22, 2019

Copyright $\odot 2019$ by author(s) and Scientific Research Publishing Inc. This work is licensed under the Creative Commons Attribution International License (CC BY 4.0).

http://creativecommons.org/licenses/by/4.0/ Open Access

\begin{abstract}
A significant amount of world trade has been carried out by maritime transportation. In 2016, world maritime trade volume increased by $2 \%$ and reached 10.3 billion tons, 55,057 global ton-miles. There has been a significant increase in quantity and tonnage of tankers, with the requirement for well qualified and experienced personnel in the maritime industry. Therefore, employment has become a serious problem. Major Oil Companies (MOCs), port states, classification societies, and flag states have increased the number of inspections on tankers due to safety concerns. Tanker inspections are becoming more difficult and inefficient due to intensive cargo operations. Inefficient, subjective or substandard inspections/evaluations are usually leading to incorrect decisions, and causing an unfair market. In addition, corrective actions cannot be carried out properly, and decision making authorities cannot give the best decisions about vessels and their operator companies due to lack of scientific methods. In this study, details are identified such as finding the root causes, identifying the risks, understanding the possible consequences, and determining the working areas during the ship crews', operators', auditors' and charterers' working and ship selection periods. Pairwise comparisons were carried out by means of surveys on ship masters (captains), chief officers, deck officers, and superintendents. Five criteria-Crew, Equipment, Company, Structure, and ISM (International Safety Management) were weighted using Analytical Hierarchy Process (AHP). Finally, Bridge Safety Support System (BSSS) was developed according to criteria weights. In this way, best choices can be offered to ship charterers about which ship is better for a company's interests. And, carrying out bridge inspections and corrective actions will be more reliable and effective for maritime transportation. Statistical data and vessel improvements will be obtained in BSSS. As a result, fair market conditions will be available in maritime industry with the help of this study.
\end{abstract}




\section{Keywords}

Tanker, Bridge, Safety, Inspection Score, Operational Risk

\section{Introduction}

Tankers (crude oil, chemical, product and liquefied gas tankers) have a significant market share in the world maritime trade [1]. ISM Code provides a good safety management culture, but its implementations still have some concerns which have been seen during vessel inspections [2]. These concerns are revealing the necessities of new inspection system developments. Bridge Safety Support System (BSSS) was developed to eliminate these concerns.

The frequency of accidents in a system is an indication of the system safety [3]. From this point of view, it can be understood that safety requirements which determine the ISM quality of a ship are mandatory components. However, reducing the measures of these requirements leads to lower quality as well as bringing several risks together. The basic requirements to ensure the safety and security of ships are as follows [4]:

- Ensuring that ships are constructed and equipped as required;

- Ensuring that ships are prepared for sea operations;

- Providing basic navigation conditions for safe and secure operation of ships at sea;

- Ensuring that ships can independently operate safely and securely at sea;

- Equipping ships with reliable alarm systems and providing assistance to them;

- Ensuring the anti-terrorist security of ships and port facilities.

The percentage of substandard ships is estimated around 10\% - 15\% by Organisation for Economic Co-operation and Development (OECD). The industry solution for this issue is to perform vetting inspections on tankers [5]. However, tanker bridge inspections have to be performed in order to enhance the profitability of maritime trade, environmental awareness, and human safety. The objective of a bridge inspection is to identify the administrative and operational faults, deficiencies and nonconformities and find the most efficient solutions. During these inspections, it will be examined if a ship has the required procedures, rules and policies during navigation, port period, anchorage, and berthing/unberthing maneuvers, and they are put into practice or not.

In this study, only bridge inspection is discussed because entire ship inspection consideration requires a much more comprehensive study. When the reliability and acceptability were proved for this approach method, it can be applied to other vessel components. Thus, with the evaluation of the individual systems, it is possible to recommend a complete inspection of an entire ship.

Until recent days, there hasn't been any weight given to the deficiencies which were found on ships, and all of them were considered at a similar importance level. Nonetheless, most of the inspection assessments usually included subjec- 
tive and verbal evaluations. All deficiencies were classified as non-conformities and major non-conformities according to ISM Code [6]. This study will be decisive in terms of what way and how to improve the quality of Tanker Management Self Assessments (TMSA). The deficiencies which were weighted according to their importance by vetting authorities will reveal how risky a ship is to perform seaborne operations. It will enable ship operators to eliminate deficiencies more efficiently with the help of this study. In addition, time and labor loss will be avoided by carrying out ship inspections with a scientific method.

Bridge inspection checklists are formed by five main criteria which are Crew, Equipment, ISM, Structure, and Company by Oil Companies International Marine Forum Ship Inspection Report Programme (SIRE) [7] when the inspection items are examined in detail. Therefore, in this study, all deficiencies which can be found on the bridge are classified by the five criteria listed above. Pairwise comparisons are carried out using Analytical Hierarchy Process (AHP) among Ship Masters, Chief Officers, Deck Officers, and Superintendents for these criteria. Bridge Safety Support System (BSSS) is developed using above five criteria according to their weights, and their deficiency effect scores. A score is calculated for each criterion as per survey results. Final BSSS Score is calculated in the combination of Vessel Quality Score and Vessel Performance Score.

\section{Literature Survey}

Profitability is one of the most important criteria in maritime industry as it is in all industries. Income and expenditure tables need to be well calculated to ensure the continuity of profitability. In order to obtain a continuous income, maritime operations must be carried out according to national and international regulations. And, it is imperative to follow a cost strategy in accordance with these governing rules.

Safety culture is a structure, consisting of the combination of the rules and attitudes of individuals and organizations that determine the cost expenses of a transportation company [8]. However, ship safety has a significant impact on improved costing models. If an exemplary model is considered, it appears that cost estimates are composed of the following main components [9]:

- Vessel Data;

- Management Data;

- Chartering Data;

- Fixed Cost Data;

- Voyage Parameters;

- Variable Cost Data.

Safety performance of a ship is being measured by loss type statistics such as injuries, loss of lives, property damage, loss of time and improper operations etc [10]. Therefore, factors such as human, safety management, navigation errors, and environmental conditions are indicated to determine the safety indicators of tankers [11]. The human factor is one of the most important decisive criteria for 
the quality of ship safety [12]. The three decisive human factors were revealed after conducting a research on human factor carried out with Exploratory Factor Analysis (EFA) [13].

- Group Skills: Tolerance, Empathy, Teamwork, Flexibility, and Learning Willingness;

- Self-Knowledge: Initiative, Self-Confidence, Self-Control, Flexibility, Tranquility, and Responsibility;

- Management: Compliance, Ambition, Rule-Based Adjustment, Motivation, and Enterprise Integration.

International Maritime Organization (IMO) determines the technical requirements to prevent accidents and incidents that may occur aboard ships. The technical requirements that cannot be determined by the committees within IMO are being formed in various organizations, and put into practice in accordance with the rules of IMO. Risk assessments are one of these technical requirements. These assessments are carried out to effectively decrease the negative incidents aboard the ships as well as terminals. Terminal risk assessments are mostly related to vessel existence within the terminal region [14], but ship risk assessments are performed regardless of any location and time.

Ship inspections have to be performed to find out if all parties are following required technical requirements. However, the main purpose of a ship inspection is to decrease the deficiencies drastically and permanently. As stated previously, there are some concerns about auditor independence during inspections [15]. However, inspections sometimes may be carried out in a more detailed way in some countries other than the others [16]. This situation usually creates an unknown situation, and even an unfair market.

\section{Bridge Operations, Risks and Root Causes}

Bridge systems are generally designed to operate independently of each other to prevent interference in the event of an equipment malfunction. However, there are some systems that need to be connected and synchronized with each other on the bridge to perform proper maneuvers.

Navigational operations have high-risk factors due to the combination of many factors, and negative consequences of these operations can cause major damages. For example; it is not the only danger to strand due to trim and squat, but also the loss of maneuvering characteristics as a result of the fluctuated hydrodynamic forces on the hull that can lead to sea accidents, depending on the size of the ships [17]. However, ship domain is one of the most critical information due to avoid collisions [18].

The maneuverability of a ship is affected by many factors both externally and internally. External factors that affect the maneuverability of the ships are: shallow waters, winds, currents, waves, marine vehicles, and land structures. Internal factors are; ship speed, vessel structure, propeller, and rudder systems [19].

The navigation process is divided into the below sub-processes [20]: 
- Voyage planning;

- Steering, maneuvering and avoidance of dangers;

- Monitoring the ship's route, and environmental conditions;

- Revision of the route and considering other necessary actions when deemed;

- Recording navigation data.

Berthing, unberthing and ship to ship operations are among the most difficult and critical operations for large tanker operators [21]. The speed of the vessel is one of the most important factors in such operations. The speed of a ship, which is determined by considering external factors such as winds, currents, waves, and depths, should provide the safest maneuverability as indicated in the study of Roubos et al. [22]. Recently, navigation risk level is increasing due to growing vessel number and volumes, shore facilities, and commercial concerns [23]. Therefore, the importance of risk management is becoming more critical under these ever-growing conditions.

Risk management is the chain of coordinated activities designed to control the risks that can prevent to achieve a successful outcome [24]. Risk management should be associated with the identification and strengthening of conditions which represent the basis for the successful operation [25]. Maritime risks can be classified as follows: Equipment Risks, Operation Risks, Environmental Risks, and Third Party Risks. These risks can lead to disastrous incidents such as loss of lives, environmental pollution, or ship loss. According to a conducted survey, the rating of the factors leading to ship loss is shown in Figure 1 [26].

The implementation of various management strategies to provide human safety can significantly reduce accidents significantly while carrying hazardous materials [27]. According to international conventions, there are five components to ensure human safety at sea, which is more important than ship loss [28]:

- Human Resources (requirements);

- Shipbuilding (requirements and equipment);

- Operation (operation of management personnel);

- External Factors (structural);

- Management (coordination of the above four components).

Safety leadership on a ship is a critical element in maintaining a safety culture. According to a survey study, the most important three items for safety leadership are; shared participation, creation/configuration, and information [29]. However, two potential improvement methods have been identified to maintain safety culture; inspection, and deficiency follow up [30].

Over the past decade, Nautical Institute has investigated collisions and groundings that are related to human errors with catastrophic consequences [31]. In that study, it was revealed that $60 \%$ of events were directly related to human errors, and a large proportion of these events were outside the Vessel Traffic Services (VTS) areas [32]. The most common causes of human errors in tanker operations are as follows [33]: 


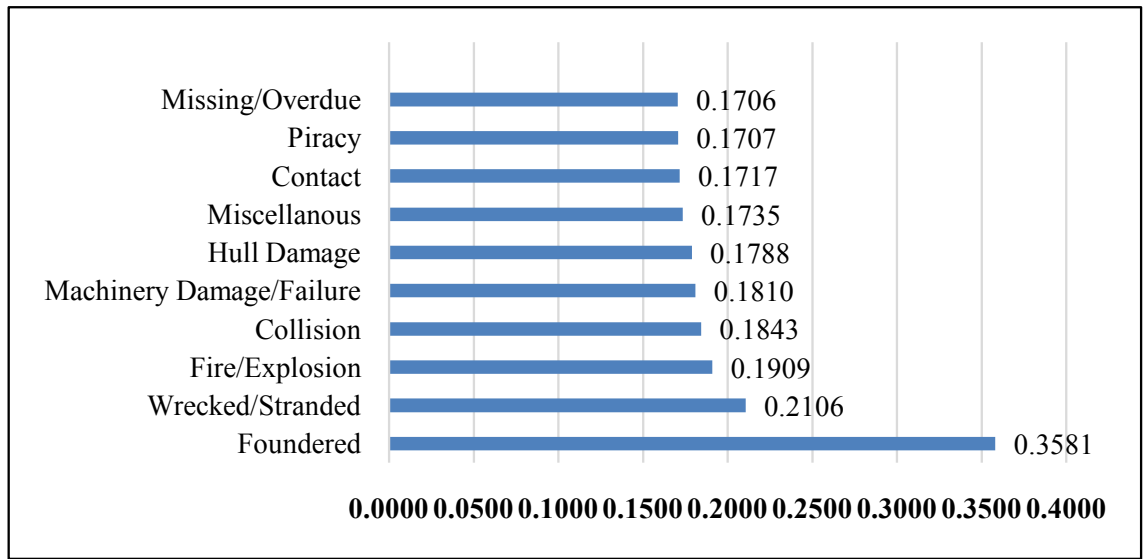

Figure 1. Rating of factors leading to ship loss.

- Fatigue;

- Insufficient communication/coordination between pilot and bridge crew;

- Insufficient technical knowledge.

The deficiencies which were found on the bridge are mostly related to the navigation of ships. These deficiencies are usually associated with task errors such as pilotage mistakes, lack of ship position, wrong maneuver, equipment misuse and misunderstanding of surrounding vessel intentions. The deficiencies linked to the task error on the bridge are shown in Figure 2 [34].

\section{Weighting of Deficiency Sources}

Working with an experienced and well-trained crew, ensuring safety orientations, developing appropriate safety goals/vision, and an effective learning system are critical for the safety culture of a transportation company [35]. Therefore, ship deficiencies are divided into five main criteria as per indicated in SIRE; Crew, Equipment, Company, Structure, and International Safety Management. These criteria were weighed by pairwise comparisons with the help of survey studies conducted with ship Masters, Chief Officers, Deck Officers, and Superintendents. The Analytic Hierarchy Process (AHP) which was developed by Saaty [36] and used as weighting method was used in this study. Masters' arithmetic means of pairwise comparisons obtained from survey results are shown in Table 1 ( $\mathrm{K}=$ Comparison, $\lambda=$ Arithmetic mean of Matrix 2).

The following equation was used for pairwise calculations.

$$
\begin{aligned}
& C_{1} C_{2} \cdots C_{n} \\
& A=\begin{array}{c}
C_{1} \\
C_{2} \\
\vdots \\
C_{n}
\end{array}\left[\begin{array}{cccc}
1 & a_{12} & \cdots & a_{1 n} \\
a_{21} & 1 & \cdots & a_{2 n} \\
\vdots & \vdots & \cdots & \vdots \\
a_{n 2} & a_{n 2} & \cdots & 1
\end{array}\right]
\end{aligned}
$$

$n$ : number of criteria to be evaluated, ci: i criterion;

aij: importance of $\mathrm{i}$ criterion to 1 criterion, aji: $1 /$ aij and aii: 1 . 


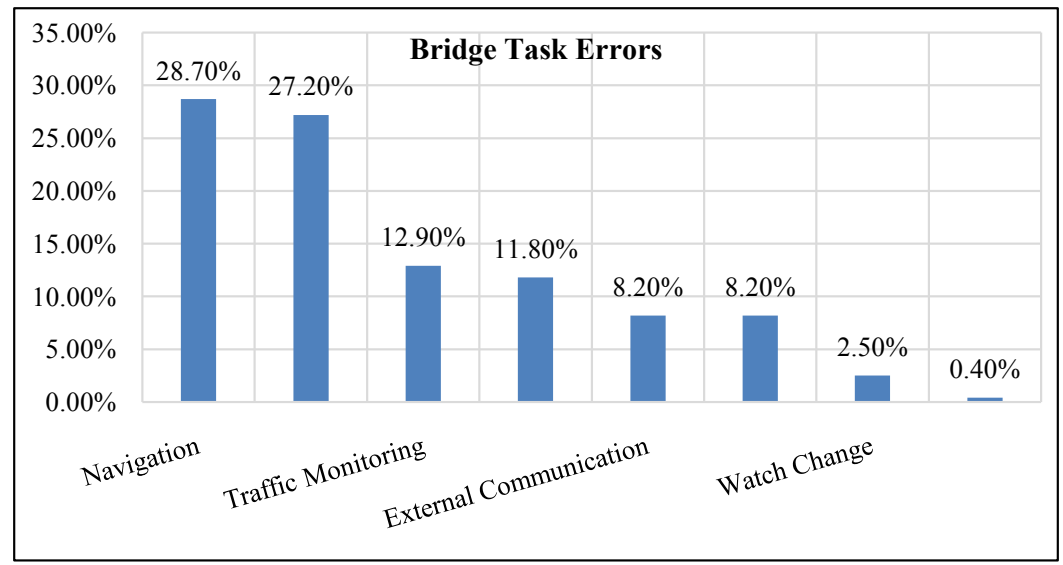

Figure 2. Deficiencies related to bridge task error.

Table 1. Masters pairwise comparison results.

\begin{tabular}{lccccccccccccccccccc}
\hline K1 & Equipment & 9 & 8 & 7 & 6 & 5 & 4 & 3 & 2 & 1 & 2 & 3 & 4 & 5 & 6 & 7 & 8 & 9 & ISM \\
\hline K2 & Equipment & 9 & 8 & 7 & 6 & 5 & 4 & 3 & 2 & 1 & 2 & 3 & 4 & 5 & 6 & 7 & 8 & 9 & Crew \\
K3 & Equipment & 9 & 8 & 7 & 6 & 5 & 4 & 3 & 2 & 1 & 2 & 3 & 4 & 5 & 6 & 7 & 8 & 9 & Structure \\
K4 & Equipment & 9 & 8 & 7 & 6 & 5 & 4 & 3 & 2 & 1 & 2 & 3 & 4 & 5 & 6 & 7 & 8 & 9 & Company \\
K5 & ISM & 9 & 8 & 7 & 6 & 5 & 4 & 3 & 2 & 1 & 2 & 3 & 4 & 5 & 6 & 7 & 8 & 9 & Crew \\
K6 & ISM & 9 & 8 & 7 & 6 & 5 & 4 & 3 & 2 & 1 & 2 & 3 & 4 & 5 & 6 & 7 & 8 & 9 & Structure \\
K7 & ISM & 9 & 8 & 7 & 6 & 5 & 4 & 3 & 2 & 1 & 2 & 3 & 4 & 5 & 6 & 7 & 8 & 9 & Company \\
K8 & Crew & 9 & 8 & 7 & 6 & 5 & 4 & 3 & 2 & 1 & 2 & 3 & 4 & 5 & 6 & 7 & 8 & 9 & Structure \\
K9 & Crew & 9 & 8 & 7 & 6 & 5 & 4 & 3 & 2 & 1 & 2 & 3 & 4 & 5 & 6 & 7 & 8 & 9 & Company \\
K10 & Structure & 9 & 8 & 7 & 6 & 5 & 4 & 3 & 2 & 1 & 2 & 3 & 4 & 5 & 6 & 7 & 8 & 9 & Company \\
\hline
\end{tabular}

The following equation was used for Consistency Index (CI). After calculation of Consistency Index, Consistency Ratio (CR) should be calculated with Random Consistency Index (RI).

$$
\begin{gathered}
\lambda=\text { weighted sum } / \text { priority } \\
C I=(\lambda-n) /(n-1) \\
C R=(C I) /(R I)
\end{gathered}
$$

Masters, Chief Officers, Deck Officers, and Superintendents consistency checks were calculated in Table 2.

Random Consistency Index (RI) is shown in Table 3.

The arithmetic means of survey results are shown in Figure 3. The number of blues columns indicates the number of people who answered in the blue region. Mean of blues indicates the mean of points in the blue region. The number of reds columns indicates the number of people who answered in the red region. Mean of reds indicates the mean of points in the red region.

AHP arithmetic means consistency check was calculated in Table 4.

The arithmetic weights were calculated in Table 5 according to the arithmetic average pairwise comparisons. 


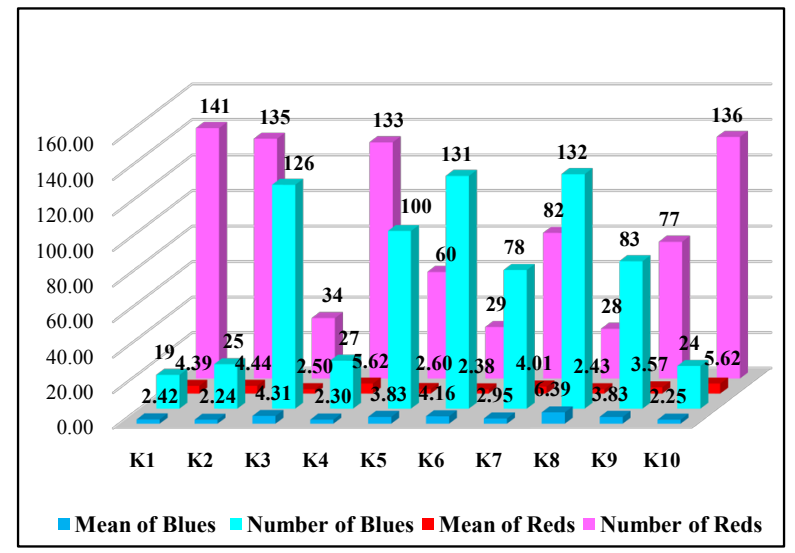

Figure 3. Masters, Officers and Superintendents survey result arithmetic means.

Table 2. AHP consistency checks.

\begin{tabular}{cccccccc}
\hline \multicolumn{2}{c}{ Masters } & \multicolumn{2}{c}{ Chief Officers } & \multicolumn{2}{c}{ Deck Officers } & \multicolumn{2}{c}{ Superintendents } \\
\hline Matrix 1 & Matrix 2 & Matrix 1 & Matrix 2 & Matrix 1 & Matrix 2 & Matrix 1 & Matrix 2 \\
\hline 1.001387 & 5.1265563 & 2.278164 & 5.3950274 & 1.4325848 & 5.5367213 & 0.9775658 & 5.142299 \\
0.652513 & 5.0864714 & 0.427045 & 5.0523168 & 0.4570135 & 5.1767403 & 0.3835590 & 5.130130 \\
1.256697 & 5.2211651 & 1.308694 & 5.4870754 & 2.0828525 & 5.6668808 & 1.6542314 & 5.470502 \\
0.307259 & 5.0896252 & 0.247831 & 5.1588019 & 0.2261208 & 5.3270273 & 0.2812823 & 5.145449 \\
1.9340730 & 5.1531267 & 1.1659772 & 5.6420252 & 1.3052664 & 5.3719241 & 2.0102228 & 5.317012 \\
$\lambda=$ & 5.1353889 & $\lambda=$ & 5.3470494 & $\lambda=$ & 5.4158587 & $\lambda=$ & 5.241078 \\
$\mathbf{n}=$ & 5 & $\mathbf{n}=$ & 5 & $\mathbf{n}=$ & 5 & $\mathbf{n}=$ & 5 \\
TG= & 0.0338472 & TG $=$ & 0.0867623 & TG $=$ & 0.1039647 & TG $=$ & 0.060270 \\
CR = & 0.0302207 & CR = & 0.0774664 & CR $=$ & 0.0928256 & CR $=$ & 0.053812 \\
\hline
\end{tabular}

Table 3. Random consistency index.

\begin{tabular}{ccccccccccc}
\hline $\mathrm{n}$ & 1 & 2 & 3 & 4 & 5 & 6 & 7 & 8 & 9 & 10 \\
\hline $\mathrm{RI}$ & 0 & 0 & 0.58 & 0.9 & 1.12 & 1.24 & 1.32 & 1.41 & 1.45 & 1.49 \\
\hline
\end{tabular}

Table 4. AHP Arithmetic means inconsistency check.

\begin{tabular}{cccc}
\hline Matrix 1 & Matrix 2 & $\mathbf{n}$ & RI \\
\hline 1.4501128 & 5.165889 & 1,2 & 0 \\
0.5198304 & 5.155854 & 3 & 0.58 \\
1.4267031 & 5.246670 & 4 & 0.90 \\
0.3136143 & 5.048807 & 5 & 1.12 \\
1.4888196 & 5.234481 & 6 & 1.24 \\
$\lambda=$ & 5.17034 & 7 & 1.32 \\
$\mathrm{n}=$ & 5 & 8 & 1.41 \\
$\mathrm{TG}=$ & 0.042585 & 9 & 1.45 \\
$\mathrm{CR}=$ & 0.038022 & 10 & 1.49 \\
\hline
\end{tabular}


Table 5. AHP results of arithmetic means and weights.

\begin{tabular}{ccccccc}
\hline & Crew & Equipment & ISM & Structure & Company & Weights \\
\hline Crew & 1.000 & 3.000 & 1.000 & 5.000 & 1.000 & \\
Equipment & 0.333 & 1.000 & 0.250 & 3.000 & 0.250 & \\
ISM & 1.000 & 4.000 & 1.000 & 3.000 & 1.000 & \\
Structure & 0.200 & 0.333 & 0.333 & 1.000 & 0.250 & \\
Company & 1.000 & 4.000 & 1.000 & 4.000 & 1.000 & \\
Total & 3.533 & 12.333 & 3.583 & 16.000 & 3.500 & \\
Crew & 0.283 & 0.243 & 0.279 & 0.313 & 0.286 & 0.281 \\
Equipment & 0.094 & 0.081 & 0.070 & 0.188 & 0.071 & 0.101 \\
ISM & 0.283 & 0.324 & 0.279 & 0.188 & 0.286 & 0.272 \\
Structure & 0.057 & 0.027 & 0.093 & 0.063 & 0.071 & 0.062 \\
Company & 0.283 & 0.324 & 0.279 & 0.250 & 0.286 & 0.284 \\
Total & 1.000 & 1.000 & 1.000 & 1.000 & 1.000 & 1.000 \\
\hline
\end{tabular}

\section{Development of Bridge Safety Support System (BSSS)}

BSSS consists of six components (five criteria and deficiency effect score according to deficiency severities); Crew, Equipment, Structure, Company, ISM, and Deficiency Effect Scores. Each score was calculated with subcomponents. BSSS Crew, Equipment, Quality and Performance Score calculations are examined in detail in the article as an example.

The Deficiency Effect Score is a component that depends on the number of deficiencies and their severities. It is calculated for each deficiency separately, and affects the BSSS final score.

Score criteria and all subcomponents are the combination of SIRE-Harmonized Vessel Particular Questionnaire (HVPQ), Vessel Inspection Questionnaire (VIQ), and Chemical Distribution Institute-Vessel Particular Questionnaire (CDI-VPQ).

160 surveys were carried out for weighing the above components (Crew, Equipment, Structure, Company, ISM, and Deficiency Effect). No specific ship, company or personal names will be given in this article due to privacy concerns. 40 Masters, 40 Chief Officers, 40 Deck Officers, and 40 Superintendents participated in these surveys. These participants were Indian, Filipino, Russian, Turkish, Greek, Ukrainian, Swedish, American and Chinese seamen. The results of these surveys are shown in Table 6 for Crew Score subcomponents and weights, and Table 7 for Equipment Score subcomponents and weights.

The BSSS calculations are based on the following equations;

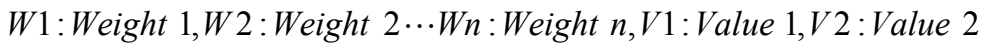

$$
W t=W 1+W 2 \cdots+W n
$$

SS1 : Subscore 1, SS2 : Subscore 2 $\cdots S S n:$ Subscore n, FS : Final Score 


$$
\begin{gathered}
S S 1=(100 \times W 1 / W t) \times V 1 S S 2=(100 \times W 2 / W t) \times V 2 \\
F S=(S S 1+S S 2 \cdots S S n) / n
\end{gathered}
$$

There are eight criteria were examined by the Crew Scoring Model. These criteria are: total sea service time for current company, total service time for current rank, total service time for current type of tankers, total service time for all types of tankers, total service time for the current tanker, total sea service time, education level, and vessel detentions during sea service periods.

Maximum Crew Score has been calculated as 314.767 according to the theoretical scenario, and Minimum Crew Score has been calculated as 5.467 according to the theoretical worst scenario by Crew Scoring Model.

Maximum Equipment Score has been calculated as 98.496 according to the theoretical best scenario, and Minimum Equipment Score has been calculated as -98.496 according to the theoretical worst scenario by Equipment Scoring Model. For instance, a real situation tanker Equipment Score calculation is shown in Table 8, and Crew Score calculation is shown in Table 9.

Each deficiency identified during the ship inspections has a Deficiency Effect Score. Deficiency Effect Scores are calculated with six subcomponents. These subcomponents are; probability of loss, probable loss consequence, frequency of deficiency, degree of importance of deficiency, root cause and deficiency correction time.

BSSS subcomponents and the best/worst scores are shown in Table 10.

Vessel Quality Score is calculated with five determining factors in accordance with their weights. Vessel Quality Score calculation is shown for best/worst scenarios in Table 11.

Vessel Performance Score is calculated by "ISM Inspection Score" in combination with "Deficiency Effect Score". Vessel Performance Score calculation and Final BSSS score for best/worst scenarios are shown in Table 12.

A tanker bridge inspection was performed to validate the rationality of BSSS. The results of this inspection are shown in Table 13.

Table 6. BSSS Crew Score subcomponents and weights.

\begin{tabular}{ccc}
\hline No. & Component & Weight \\
\hline 1 & Total Service Time for Current Company & 6.54 \\
2 & Total Service Time for Current Rank & 7.63 \\
3 & Total Service Time for Current Type of Tankers & 8.15 \\
5 & Total Service Time for All Types of Tankers & 7.81 \\
6 & Total Service Time for the Current Tanker & 6.28 \\
7 & Total Sea Service Time & 8.30 \\
8 & Education Level & 6.05 \\
\hline
\end{tabular}


Table 7. BSSS Equipment Score subcomponents and weights.

\begin{tabular}{ccc}
\hline No. & Component & Weight \\
\hline 1 & Navigation Systems & 8.25 \\
2 & Communication Systems & 7.25 \\
3 & Bridge Engine Control Systems & 8.15 \\
4 & Emergency Situation Systems & 7.55 \\
5 & Illumination Systems & 6.95 \\
6 & Deck Related Systems & 6.12 \\
\hline
\end{tabular}

Table 8. BSSS Equipment Score calculation.

\begin{tabular}{cccccc}
\hline Equipment Status & $\begin{array}{c}\text { Good } \\
\text { Order }\end{array}$ & $\begin{array}{c}\text { Partially } \\
\text { Good }\end{array}$ & Out of Order & $\begin{array}{c}\text { Back up } \\
\text { Available }\end{array}$ & Score \\
\hline Navigation Systems & 11 & 0 & 1 & 1 & 191.141 \\
Communication Systems & 4 & 3 & 1 & 1 & $\mathbf{7 9 . 9 8 7}$ \\
Bridge Engine Control Systems & 3 & 1 & 0 & 0 & $\mathbf{6 2 . 9 4 1}$ \\
Emergency Situation Systems & 4 & 0 & 1 & 0 & 49.978 \\
Illumination Systems & 1 & 0 & 1 & 1 & $\mathbf{8 . 8 2 6}$ \\
Deck Related Systems & 3 & 1 & 0 & 0 & $\mathbf{4 7 . 2 6 4}$ \\
\hline
\end{tabular}

Equipment Score $=73.356$.

Table 9. BSSS Crew Score calculation.

\begin{tabular}{|c|c|c|c|c|c|c|c|c|c|c|c|c|}
\hline \multicolumn{4}{|c|}{ Rank } & Master & $\begin{array}{l}\text { Chief } \\
\text { Off. }\end{array}$ & $\begin{array}{l}\text { 2nd } \\
\text { Off. }\end{array}$ & $\begin{array}{l}3 \text { rd } \\
\text { Off. }\end{array}$ & $\begin{array}{l}4 \text { th } \\
\text { Off. }\end{array}$ & $\begin{array}{l}\text { Chief } \\
\text { Off. }\end{array}$ & $\begin{array}{l}\text { 2nd } \\
\text { Eng. }\end{array}$ & $\begin{array}{l}\text { 3rd } \\
\text { Eng. }\end{array}$ & $\begin{array}{l}\text { 4th } \\
\text { Eng. }\end{array}$ \\
\hline \multicolumn{4}{|c|}{$\begin{array}{l}\text { Total Service Time } \\
\text { for Current Company }\end{array}$} & 5.5 & 1.8 & 1.1 & 2.5 & 1.5 & 10.2 & 1.5 & 0.5 & 2.1 \\
\hline \multicolumn{4}{|c|}{ Total Service Time at Current Rank } & 6.4 & 2.1 & 2.4 & 1.1 & 2.2 & 7.2 & 3.1 & 1.7 & 1.4 \\
\hline \multicolumn{3}{|c|}{$\begin{array}{l}\text { Total Service Time } \\
\text { on Current Tanker }\end{array}$} & & 2.8 & 1.4 & 1.4 & 1.1 & 0.4 & 4.4 & 2.5 & 1.7 & 0.9 \\
\hline \multicolumn{3}{|c|}{$\begin{array}{l}\text { Total Service Time on } \\
\text { All Types of Tankers }\end{array}$} & & 10.4 & 2.1 & 2.4 & 2.5 & 2.2 & 15.5 & 2.5 & 1.7 & 2 \\
\hline \multicolumn{3}{|c|}{$\begin{array}{l}\text { Total Service Time } \\
\text { on Current Tanker }\end{array}$} & & 0.4 & 0.3 & 0.25 & 0.5 & 0.45 & 0.1 & 0.4 & 0.45 & 0.15 \\
\hline \multicolumn{3}{|c|}{ Total Sea Service Time } & & 15.8 & 5.5 & 3.1 & 2.5 & 2 & 20.2 & 4.2 & 2.4 & 2.9 \\
\hline \multicolumn{3}{|c|}{ Education Level } & & 4 & 3 & 3 & 2 & 2 & 3 & 4 & 2 & 3 \\
\hline \multicolumn{3}{|c|}{ Vessel Detentions during } & & 10 & 5 & 10 & 10 & 10 & 5 & 10 & 1 & 5 \\
\hline 63.652 & 20.832 & 12.730 & 28.93 & & 17.360 & 118.046 & & 7.360 & 5.78 & 787 & & .304 \\
\hline 86.413 & 28.354 & 32.405 & 14.85 & & 29.704 & 97.215 & & 1.856 & 22.9 & 953 & & .903 \\
\hline 40.382 & 20.191 & 20.191 & 15.86 & & 5.769 & 63.458 & & 5.056 & 24.5 & 518 & & .980 \\
\hline 143.734 & 29.023 & 33.169 & 34.55 & & 30.405 & 214.219 & & 1.551 & 23.4 & 495 & & 641 \\
\hline 4.445 & 3.334 & 2.778 & 5.55 & & 5.001 & 1.111 & & .445 & 5.00 & 001 & & 667 \\
\hline 232.065 & 80.782 & 45.532 & 36.71 & & 29.375 & 296.691 & & 1.688 & 35.2 & 250 & & .594 \\
\hline 42.824 & 32.118 & 32.118 & 21.41 & & 21.412 & 32.118 & & 2.824 & 21.4 & 412 & & .118 \\
\hline 101.752 & 50.876 & 101.752 & 101.7 & & 101.752 & 50.876 & & 1.752 & 10.1 & 175 & & .876 \\
\hline 89.409 & 33.189 & 35.084 & 32.45 & & 30.097 & 109.217 & & .567 & 18.5 & 574 & & .385 \\
\hline
\end{tabular}

Crew Score $=46.331$. 
Table 10. BSSS subcomponents and the best/worst scores.

\begin{tabular}{cccc}
\hline No. & Component & Best Score & Worst Score \\
\hline 1 & Crew Score & 512.56 & 5.47 \\
2 & Equipment Score & 512.56 & -98.50 \\
3 & Operator Score & 1666.67 & 229.51 \\
4 & Structure Score & 1666.67 & 236.56 \\
5 & ISM Inspection Score & 341.18 & -682.37 \\
6 & Deficiency Effect Score & 1000.00 & -8166.67 \\
\hline
\end{tabular}

Table 11. BSSS Vessel Quality Score calculation.

\begin{tabular}{cccc}
\hline Weights & Score Type & Best Score & Worst Score \\
\hline 0.27886 & Crew Score & 512.56 & 5.47 \\
0.09952 & Equipment Score & 98.50 & -98.50 \\
0.28642 & Company Score & 1666.67 & 229.51 \\
0.06050 & Structure Score & 1666.67 & 236.56 \\
0.27471 & ISM Inspection Score & 341.18 & -682.37 \\
0.75000 & Quality Score & 824.66 & -115.68 \\
0.25000 & Previous Quality Score & 824.66 & -115.68 \\
0.41000 & Weighted Quality Score & 824.66 & -115.68 \\
\hline
\end{tabular}

Table 12. BSSS Vessel Performance Score and Final BSSS Score calculation.

\begin{tabular}{cccc}
\hline Weights & Score Type & Best Score & Worst Score \\
\hline 0.45000 & ISM Inspection Score & 341.18 & -682.37 \\
0.55000 & Deficiency Effect Score & 1000.00 & -8166.67 \\
0.70000 & Performance Score & 703.53 & -4798.73 \\
0.30000 & Previous Performance Score & 703.53 & -4798.73 \\
0.59000 & Weighted Performance Score & 703.53 & -4798.73 \\
& Final BSSS Score & 753.20 & -2878.68 \\
\hline
\end{tabular}

Table 13. Tanker bridge inspection score calculation.

\begin{tabular}{lccccc}
\hline Weights & Score Type & Score & Weights & Score Type & Score \\
\hline $\mathbf{0 . 2 7 8 8 6}$ & Crew Score & 185.69 & 0.45000 & ISM Inspection Score & 91.94 \\
$\mathbf{0 . 0 9 9 5 2}$ & Equipment Score & 215.36 & 0.55000 & Deficiency Effect Score & 735.17 \\
$\mathbf{0 . 2 8 6 4 2}$ & Company Score & 1398.99 & 0.70000 & Performance Score & 445.71 \\
$\mathbf{0 . 0 6 0 5 0}$ & Structure Score & 1302.63 & 0.30000 & Previous Performance Score & 842.00 \\
$\mathbf{0 . 2 7 4 7 1}$ & ISM Inspection Score & 91.94 & 0.59000 & Weighted Performance & 564.60 \\
$\mathbf{0 . 7 5 0 0 0}$ & Quality Score & 577.98 & & Score & \\
$\mathbf{0 . 2 5 0 0 0}$ & Previous Quality Score & 305.25 & & & \\
$\mathbf{0 . 4 1 0 0 0}$ & Weighted Quality & 509.80 & & & \\
\hline
\end{tabular}

Final BSSS Score $=542.13$. 


\section{Conclusions}

Some conclusions were reached by analyzing the arithmetic means of the pairwise comparison survey results:

- The ISM criterion has the 4 th-degree superiority to the equipment criterion. This indicates that it is possible to have the correct equipment aboard ships with a good ISM system;

- The Company criterion has the 4 th-degree superiority to the equipment criterion. There is always pressure on maritime companies due to their responsibilities, and this pressure is considered by seafarers as a superior criterion in order to provide the right equipment;

- It is observed that there is no superiority between ISM and Company criteria. Development and implementation of ISM system are directly dependent on the human factor, and determination of any superiority between them may lead to various problems;

- The Crew criterion has the 5th-degree superiority to the Structural criterion. Considering that ship gears and equipment must meet certain standards, their proper usage is directly dependent on the ship crew. This situation is a sign of the importance of working with a qualified crew;

- The Crew and Company criteria do not have any superiority to each other. No superiority is determined because a company has the greatest power in choosing the ship crew and appropriate ISM system applications.

The difference between the best and worst final BSSS score is 3631.88. This variance can be classified according to specific safety margins by decision-maker authorities such as Major Oil Companies (MOC), Port States, Flag States, Classification Societies or Insurance Companies, such as Protection and Indemnity (P\&I), or Hull and Machinery (H\&M).

Some authorities may restrict a ship from any movements due to the BSSS system scores. For example, a major oil company may refuse a ship due to crew score, a port state may not approve the passage of a channel due to the structure score of a ship, or an insurance company may determine the insurance premiums according to the BSSS scores.

\section{Conflicts of Interest}

The authors declare no conflicts of interest regarding the publication of this paper.

\section{References}

[1] United Nations (2017) Review of Maritime Transport 2017. United Nations Conference on Trade and Development (UNCTAD), New York and Geneva, 6.

[2] Bhattacharya, Y. (2015) Measuring Safety Culture on Ships Using Safety Climate: A Study among Indian Officers. International Journal of e-Navigation and Maritime Economy, 3, 51-70. https://doi.org/10.1016/j.enavi.2015.12.006

[3] Hanninen, M. and Kujala, P. (2014) Bayesian Network Modeling of Port State Control Inspection Findings and Ship Accident Involvement. Expert Systems with Ap- 
plications, 41, 1632-1646. https://doi.org/10.1016/j.eswa.2013.08.060

[4] Urbanski, J., Morgas, W. and Kopacz, Z. (2008) The Safety and Security Systems of Maritime Navigation. The Journal of Navigation, 61, 529-535. https://doi.org/10.1017/S0373463308004712

[5] Knapp, S. and Franses, P.H. (2006) Analysis of the Maritime Inspection Regimes-Are Ships over Inspected? Econometric Institute Report 2006-30. Econometric Institute, Erasmus University, Rotterdam.

[6] ISM CODE (2018) International Safety Management Code. International Maritime Organization. IMO Publishing, London.

[7] SIRE (2018) Ship Inspection Report Programme. Vessel Inspection Questionnaires for Oil Tankers, Combination Carriers, Shuttle Tankers, Chemical Tankers and Gas Tankers, Seventh Edition (VIQ 7). Oil Companies Inspection Forum (OCIMF), London.

[8] Grabowski, M., You, Z., Song, H., Wang, H. and Merrick, J.R.W. (2010) Sailing on Friday: Developing the Link between Safety Culture and Performance in Safety-Critical Systems. IEEE Transactions on Systems, Man, and Cybernetics-Part A: Systems and Humans, 40, 263-284. https://doi.org/10.1109/TSMCA.2009.2035300

[9] Enezy, O.A., Hassel, E., Sys, C. and Vanelslander, T. (2017) Developing a Cost Calculation Model for Inland Navigation. Research in Transportation Business \& Management, 23, 64-74. https://doi.org/10.1016/j.rtbm.2017.02.006

[10] Grabowski, M., Ayyalasomayajula, P., Merrick, J. and Mccafferty, D. (2010) Accident Precursors and Safety Nets: Leading Indicators of Tanker Operations Safety. Maritime Policy \& Management, 34, 405-425.

https://doi.org/10.1080/03088830701585084

[11] Wen-Kai, K.H., Huang, S.H.S. and Yeh, R.F.J. (2015) An Assessment Model of Safety Factors for Product Tankers in Coastal Shipping. Safety Science, 76, 74-81. https://doi.org/10.1016/j.ssci.2015.02.022

[12] Li, S., Meng, Q. and Qu, X. (2012) An Overview of Maritime Waterway Quantitative Risk Assessment Models. Risk Analysis, 32, 496-512. https://doi.org/10.1111/j.1539-6924.2011.01697.x

[13] Cordon, J.R., Mestre, J.M. and Walliser, J. (2017) Human Factors in Seafaring: The Role of Situation Awareness. Safety Science, 93, 256-265. https://doi.org/10.1016/j.ssci.2016.12.018

[14] Vidmar, P. and Perkovic, M. (2018) Safety Assessment of Crude Oil Tankers. Safety Science, 105, 178-191. https://doi.org/10.1016/j.ssci.2018.02.009

[15] Goodwin, J. and Yeo, T.Y. (2001) Two Factors Affecting Internal Audit Independence and Objectivity: Evidence from Singapore. International Journal of Auditing, 5, 107-125. https://doi.org/10.1111/j.1099-1123.2001.00329.x

[16] Graziano, A., Cariou, P., Wolff, F.C., Mejia, M.Q. and Hinrichs, J.U.S. (2018) Port State Control Inspections in the European Union: Do Inspector's Number and Background Matter? Marine Policy, 88, 230-241. https://doi.org/10.1016/j.marpol.2017.11.031

[17] Lee, S. and Hong, C. (2017) Study on the Course Stability of Very Large Vessels in Shallow Water Using CFD. Ocean Engineering, 145, 395-405. https://doi.org/10.1016/j.oceaneng.2017.09.064

[18] Dinh, G.H. and Im, N. (2016) The Combination of Analytical and Statistical Method to Define Polygonal Ship Domain and Reflect Human Experiences in Estimating Dangerous Area. International Journal of e-Navigation and Maritime Economy, 4, 97-108. https://doi.org/10.1016/j.enavi.2016.06.009 
[19] Liu, J., Hekkenberg, R., Erik, R. and Hopman, H. (2015) Literature Review on Evaluation and Prediction Methods of Inland Vessel Manoeuvrability. Ocean Engineering, 106, 458-471. https://doi.org/10.1016/j.oceaneng.2015.07.021

[20] Kopacz, Z., Morgas, W. and Urbanski, J. (2003) The Ship's Navigation Function, Ship's Navigation Processes, and Ship's Navigational Information. The Royal Institute of Navigation. The Journal of Navigation, 56, 101-109. https://doi.org/10.1017/S0373463302002060

[21] Oda, H., Okuyama, E. and Shimizu, E. (2010) Ship to Ship Operations Monitoring System Using High Accuracy DGPS. 8th IFAC Conference on Control Applications in Marine Systems, Rostock-Warnemunde, 15-17 September 2010, 62-66. https://doi.org/10.3182/20100915-3-DE-3008.00021

[22] Roubos, A., Groenewegen, L. and Peters, D.J. (2017) Berthing Velocity of Large Seagoing Vessels in the Port of Rotterdam. Marine Structures, 51, 202-219. https://doi.org/10.1016/j.marstruc.2016.10.011

[23] Cho, I., Kim, I. and Lee, Y. (2010) The Introductory Concept of Maritime Safety Audit as a Tool for Identifying Potential Hazards. Journal of Navigation and Port Research International Edition, 34, 699-704. https://doi.org/10.5394/KINPR.2010.34.9.699

[24] Leveson, N.G. (2011) Engineering a Safer World. Aeronautics and Astronautics and Engineering System Division, Massachusetts Institute of Technology, MIT Press, Cambridge.

[25] Osiris, A.V.B., Floris, G., Vladimir K., Pentti, K. and Jakub, M. (2016) Risk Management Model of Winter Navigation Operations. Marine Pollution Bulletin, 108, 242-262. https://doi.org/10.1016/j.marpolbul.2016.03.071

[26] Chen, J., Zhanga, F, Yanga, C., Zhanga, C. and Luoa, L. (2017) Factor and Trend Analysis of Total-Loss Marine Casualty Using a Fuzzy Matter Element Method. International Journal of Disaster Risk Reduction, 24, 383-390. https://doi.org/10.1016/j.ijdrr.2017.07.001

[27] Landucci, G., Antonioni, G., Tugnoli, A., Bonvicini, S., Molag, M. and Cozzani, V. (2017) Hazmat Transportation Risk Assessment: A Revisitation in the Perspective of the Viareggio LPG Accident. Journal of Loss Prevention in the Process Indus tries, 49, 36-46. https://doi.org/10.1016/j.jlp.2016.08.009

[28] Faturachmana, D. and Mustafa, S. (2012) Performance of Safety Sea Transportation. Procedia-Social and Behavioral Sciences, 57, 368-372.

https://doi.org/10.1016/j.sbspro.2012.09.1199

[29] Kim, T. and Gausdal, A.H. (2017) Leading for Safety: A Weighted Safety Leadership Model in Shipping. Reliability Engineering and System Safety, 165, 458-466. https://doi.org/10.1016/j.ress.2017.05.002

[30] Knapp, S. (2006) The Econometrics of Maritime Safety-Recommendations to Enhance Safety at Sea. PhD Thesis, Erasmus University, Rotterdam.

[31] Hussein, A.W., El-Dessouky, U.M., El-Kilani, H.S. and Hegazy, E.H. (2016) Grounding Contingency Plan for Intact Double Hull Tanker. Alexandria Engineering Journal, 55, 235-241. https://doi.org/10.1016/j.aej.2015.10.017

[32] Gale, H. and Patraiko, D. (2007) The Role of e-Navigation. Improving Navigational Safety, Seaways, July 2007, 4-8.

[33] Altun, M.H.A., Kum, S. and Cicek, I. (2014) IAMU Conference 15AGA. Human Errors on Chemical Tanker Loading-Discharging Operations. Proceeding of Innovation in Maritime Education, Training and Research, International Association of Maritime Universities, Tasmania, 27-30 October 2014, 1-11. 
[34] Graziano, A., Teixeira, A.P. and Soares, C.G. (2016) Classification of Human Errors in Grounding and Collision Accidents Using the Tracer Taxonomy. Safety Science, 86, 245-257. https://doi.org/10.1016/j.ssci.2016.02.026

[35] Grabowski, M., Ayyalasomayajula, P., Merrick, J., Harrald, J.R. and Roberts, K. (2007) Leading Indicators of Safety in Virtual Organizations. Safety Science, 45, 1013-1043. https://doi.org/10.1016/j.ssci.2006.09.007

[36] Saaty, T.L. (1977) Scaling Method for Priorities in Hierarchical Structures. Journal of Mathematical Psychology, 15, 234-281.

https://doi.org/10.1016/0022-2496(77)90033-5 